\title{
The Study of Small Town Planning Based on S.E.T. Model -The West District of Suihua City, Heilongjiang Province, China as an Example
}

\author{
Ming Lu, Jun Xing, Yu Chen* \\ Harbin Institute of Technology, China
}

Copyright (C) 2015 by authors, all rights reserved. Authors agree that this article remains permanently open access under the terms of the Creative Commons Attribution License 4.0 International License

\begin{abstract}
The disadvantage of imbalance while using a single mode for the development of urban is becoming highlighted $^{[1]}$. In order to solve this problem, eight cities and towns published in China have used the S.E.T. mode (Service-Ecology-Transit-Oriented Development) planning. In this paper, the S.E.T. mode was used in the planning of the West District of Suihua City, Heilongjiang Province, China, and by the analysis of the land use, the spatial structure and the function structure, we made an evaluation of the advantages and disadvantages of the S.E.T., and verified its feasibility and scope of application. And it would be significant to small town planning, the non-agricultural population of which is less than 200,000 in China, in the future.
\end{abstract}

Keywords S.E.T. Mode, Small Town Planning, The New West District of Suihua, Multi-factor-oriented

\section{Introduction}

Urban planning in China is in charge of the planning administrative department of local government, and it is common done with cooperation of architects, urbanists, traffic experts, and others experts according to the locality. Because of the change of the development strategy of urban planning in China, the planning of small towns is getting more and more important after the eighteenth national congress of the communist party of China, which is the most important congress of statesmen in China.

SOD (Service-Oriented Development), EOD (Ecology-Oriented Development) and TOD (Transit-Oriented Development) are three modes to solve different problems in cities in China. Eight cities and towns published have applied them together to planning, and named it the S.E.T. mode. Nevertheless, the S.E.T. mode is not suitable for all small towns. It has a certain scope of application. Besides, the study about the scientific nature, the applicable scope of the S.E.T. mode, and the results of applying it to actual project is not enough.

Based on the background, we take the West District of Suihua City, Heilongjiang Province, China as an example. We have applied the S.E.T. mode to the planning. Through the analysis of the land use index, the spatial structure, function and structure of the West District of Suihua City after the planning, we evaluated the advantages and disadvantages of S.E.T. mode, and verified its feasibility, scientific nature and scope of application, forming a scientific and perfect planning method.

\section{Analysis of S.E.T. Mode}

The S.E.T. mode is a new urban development strategy. It is put forward to solve the problem that developing a city with a single strategy is one-sided, and leads to the unbalanced development of the city. The key point of the S.E.T. mode is dividing the structure of a city into a public service facilities system, an ecological green land system and a road traffic system. Take advantage the SOD, EOD and TOD respectively for each system planning, overlay different systems, and integrated organize the elements, so that the planning is perfectly made. (Figure 1)

\subsection{Implications of SOD, EOD, and TOD}

SOD, namely Service-Oriented Development, is used in order that the facilities could activate the whole district ${ }^{[2]}$. EOD is also called Ecology-Oriented Development. It is a method used to improve the living environment with the plan of the ecological garden system ${ }^{[3]}$. TOD is also called Transit-Oriented Development. With the construction of public transport, it is used to achieve better convenient transportation accessibility. 


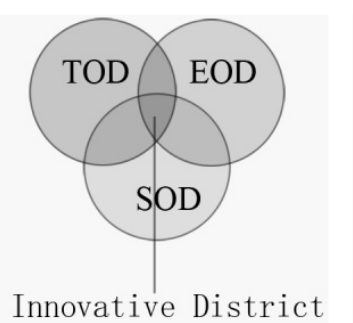

S.E.T

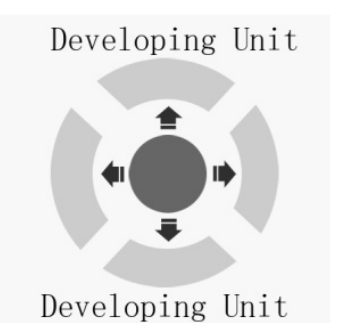

SOD

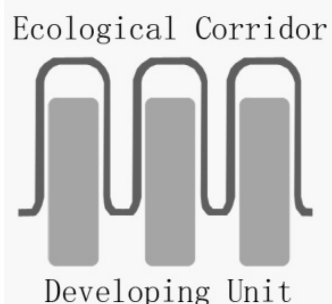

EOD

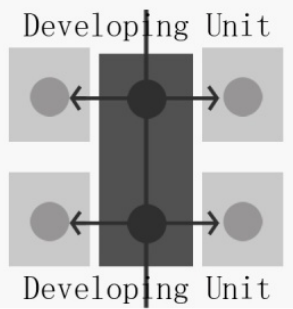

TOD

Source: the Author Made

Figure 1. Analysis of S.E.T. Mode

\subsection{The Comprehensive Implementation of S.E.T.}

The comprehensive implementation process of S.E.T. mainly includes three steps. First of all, take advantage the SOD, EOD and TOD respectively for the public service facilities planning, the green space system planning and the public transportation system planning. Then overlay different systems, and integrated organize the elements. Finally, integrate different systems. It is the key of the S.E.T. mode, which includes the following aspects:

1 Integrate adjacent nodes in different systems. For example, construct the mixed public transport nodes with the TOD mode. We can combine the nodes with the public service facilities, to make it mixed nodes of the town, which would save urban land use, and improve the nodes. We should pay more attention to the nodes combined with the green space nodes, and make them not only meet the functional requirements, but also maintain a good ecological environment, forming different landscape.

2 Weigh the land use in different systems and determine it. For example, somewhere may be planned as a garden with the EOD mode, and be planned for public service facilities with the SOD mode. It depends when the conflict happens. We should choose the node function generally, and keep the integrity of the axis, and meet the need of the mass. For example, somewhere may be planned as a garden with the EOD mode, and be planned for recreational purposes with the SOD mode, then it should be planned as a garden.

3 The reduced parts in the previous step should be compensated. These parts should be planned in other area of the town. For example, the recreational purposes in the above assumptions should be planned in somewhere else. Different kinds of parts should be compensated in different areas. For land for public interest, such as public green space or city squares, the compensation should be precise, and the compensation ratio should be greater than 1 , and the quality of the land should be equal to or be better than that before. For land for public service, such as schools or hospitals, the compensation ratio should be 1 , and the quality of the land should be similar to that before. For land for profit, such as bars or KTV, the compensation ratio can be cut according to the actual situation.

4 Integrated regulate the comprehensive land use. After the integrating of different systems, the structure of the city or the town has been changed. Therefore, the comprehensive land use should be reviewed and overall adjusted.

\section{Profile of the West District of Suihua City, Heilongjiang Province, China}

The region of Suihua is located in the south of Heilongjiang Province, China, by the Hulan river valley in the Songnen plain. It is $305 \mathrm{~km}$ wide from the east to the west, and $308 \mathrm{~km}$ from the north to the south. It is in the urban agglomeration of the Songnen plain, which is in the center of the Harbin-Dalian-Qiqihar industrial corridor and affected by the direct radiation of the industrial center. It is one of the deputy center cities of Harbin city economic circle and the center city in central Heilongjiang Province. The development of Suihua plays an important role in promoting the development of the north of Heilongiiang Province.

The West District of Suihua City is located in the west of Kangzhuang Road, which is a key development area of Suihua. The structure of the main road in Suihua is two east-west roads, S304 and S305, as well as one north-south road, the Kangzhuang Road. There are several communities along the Kangzhuang Road, and the architectural form is unified. There are several villages, some wasteland and farmland in the rest area.

The structure of road network in Suihua is imperfect, which is unable to meet the demand of urban development. The utilization rate of land is low, with a large number of idle lands in the west. The public service facilities present cannot meet the demand of the development of the district. There have been some infrastructures in the area, such as fire stations, water supply and drainage, power supply companies and communication companies, but the scales of them are limited. There is a lack of characteristic in the city, without perfect protection and utilization of resources. The landscape is disorderly, and the landscape in the entrance of the city needs transformation. There is a lack of landmark landscape nodes. 

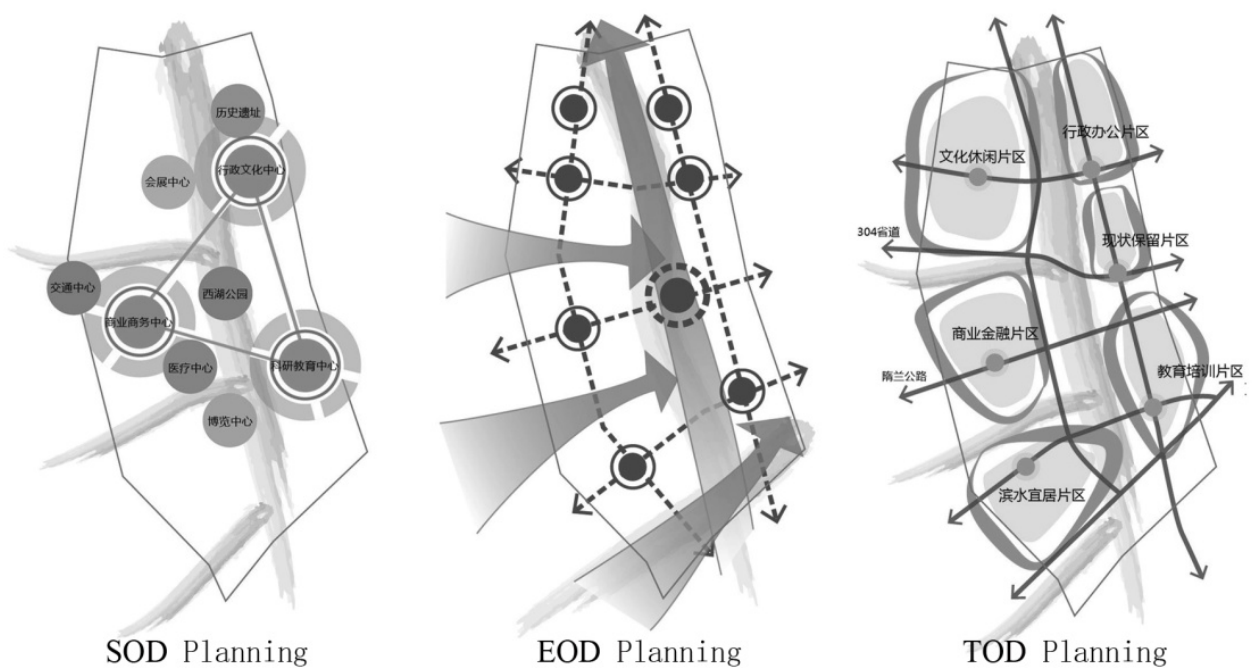

Source: the Author Made

Figure 2. Systems Planning of S.E.T.

\section{The Plan of the West District of Suihua City with S.E.T.}

Make the plan for the West District with the S.E.T. mode, the process including three steps, systems planning, system overlay and system integration.

\subsection{Systems Planning}

During the first stage of planning, take advantage the SOD, EOD and TOD respectively for the public service facilities planning, the green space system planning and the public transportation system planning. (See Figure 2)

\subsection{System Overlay}

After planning for different systems, overlay them, forming a compound structure. With the system overlay, the structure of the West District would be: six regions, four cores, one axis, three belts, and multi-node.

Six regions refers to the leisure culture area, commercial finance area, waterfront habitable area, administrative office area, the present situation reserved area, and education training area separated by the wedge green space and the central green axis.

Four cores refer to the administration center, the business service center and the scientific research training center and the ecological landscape center of the West Lake Park.

One axis refers to the central waterfront landscape axis across the south and north of the new district.

Three belts refer to the two wedge green belts and the main canal, which separates different groups.

Multi-node refers to the deputy nodes of public service facilities, and landscape, as well as mixed nodes with the core of bus station.

\subsection{System Integration}

After overlaying different systems, comprehensively adjust them.

The core of the large public service facilities in the district, the public service facilities within the area, and the green space in the groups are concentrated in the center of each community. Integrate them and improve the service level.

Integrate the nodes of the public traffic network system and the public service facilities. The bus lines are set along the west side of central green axis, avoiding crossing the communities. Keep the distance between each bus station and each community within five minutes' walk.

While comprehensively arranging the public service facilities and the green space in the groups, the green space may be occupied, which needs to be compensated. Make it along the road within the groups, forming a green belt network throughout the groups. Then the green seeps into each tiny living group.

Finally, on the basis of the present situation and actual needs of the district, reserve a site of the plane fort, a public cultural entertainment square, and build a gym. Take the reservoirs on the north of the central green axis as a part of the green space landscape system. Construct a node of garden at the junction of the central green axis and the main canal in the south.

\section{Implications}

The West District of Suihua City is planned with a total land area of $15.54 \mathrm{~km}^{2}$. After planned with the S.E.T. mode, the residential land area ratio was $37.90 \%$, the land for public management and public service facilities 9.35\%, land for commercial services facilities $4.31 \%$, road traffic land $17.39 \%$, public green land and waters accounted for $29.60 \%$, other land accounted for $1.45 \%$.

It can be seen that after planned with the S.E.T. mode, the ratio of the public green space and the public open space is 
$19.60 \%$ higher than before, which can provide high quality living environment for the residents. However, it can provide fewer employment opportunities relatively.

The overall effect is good that planning the West District with the S.E.T. mode. Compared with residents in the old district, the ones in the new district enjoy a better living environment. Due to the improvement of the public transport system, it is quite convenient that the residents travel between the old district and the new.

In terms of employment, as some farmland is reserved at the outer end of the wedge green space, some residents are still engaged in agricultural activities, as part of the economic income. There are still a large number of people living in the new district working in the old district, taking public transport as a daily commuter traffic way. There are also a certain amount of public service facilities and business facilities built in the new district, and some people work in these shopping malls, schools, and convention and exhibition center.

According the results of the planning, taking advantage of the S.E.T. mode in the planning of small towns, the public service facilities can be well arranged, and the towns can be developed in a balance. Besides, it can provide a high quality of living conditions and living environment, as well as convenient public transportation for the residents. However, only a few jobs can be provided, which may lead to the employment problem. The economic growth of the towns would not be so fast as well.

Therefore, the S.E.T. mode is suitable to the small towns in which the economic development has been stable and people take more about living conditions and living environment into consideration. In addition, because of the demands of the structure, the S.E.T. mode is more suitable to the new district of a town which has been developed in a low level. To solve the problem of less employment, pollution-free industry area, urban farmland can be developed, and public transportation can be improved.

\section{Acknowledgements}

We are very grateful to be sponsored by the National Project of Scientific and Technical Supporting Programs Funded by Ministry of Science \& Technology of China (Grant No. 2013BAJ12B02), and we thank the experts very much for their appropriate and constructive suggestions to improve this paper.

\section{REFERENCES}

[1] Hailong He. Problems and Solutions of the Construction of Small Towns Under the New Town Planning [J]. Modern Agricultural Technology. 2014, 15:349-351.

[2] Qing WANG. Urban New Development Mode Based on Large-scale Public Facility [J]. Modern Urban Research, 2008, 11:47-53.

[3] Haitao Chen. Research on Urban Green Space Planning Tactics under the Model of Eco-oriented Development [D]. Huazhong University of Science \& Technology, 2012.

[4] Hao Li. Improvemnet Of Urban Planning Under The Ideal Of Eco-city [D]. China Academy of Urban Planning and Design, 2012.

[5] Minsheng Ding. Study of the Eco-oriented Urban General Layout [D]. Master Dissertation of Suzhou University of Science and Technology, 2007.

[6] Baoxing Qiu. Complicated Science And Urban Planning Reform [J].City Planning Review, 2009, 04:11-26. 